\section{Estudo \\ Ecibate}

em Cestão

Plamejamento
Revista Estudo \& Debate, Lajeado, v. 26, n. 1, 2019. ISSN 1983-036X

DOI: http://dx.doi.org/10.22410/issn.1983-036X.v26ila2019.1881

\title{
FATORES DETERMINANTES DO CONSUMO DE AÇO: UM PAINEL DE DADOS PARA PAIISES
}

\author{
Louyze Anne Mayonne Lima Santos ${ }^{1}$, Hilton Manoel Dias Ribeiro ${ }^{2}$
}

\begin{abstract}
Resumo: Diante da observação das oscilações do consumo de aço nas maiores potências siderúrgicas mundiais, o presente estudo tem por objetivo analisar como alguns fatores sistêmicos, tais como as taxas de industrialização, de importaçáo, de urbanização e salário médio, podem influenciar o desenvolvimento do setor siderúrgico, medido a partir do consumo de aço per capita dos países. Para tanto, foram selecionados 133 países, com base em dados extraídos da World Steel Association e do Banco Mundial, para os anos de 1995 a 2016. A estratégia empírica envolve a análise de dados em painel e os principais resultados indicam a presença de heterogeneidade não observada e a necessidade de controle dos efeitos aleatórios, sendo que os coeficientes das variáveis foram, em sua maioria, positivos, revelando que fatores econômicos sistêmicos como salário médio, taxas de urbanização, importação e industrialização são variáveis importantes para a discussão sobre o desenvolvimento industrial e econômico dos países, ligado aqui ao consumo de aço, insumo básico de uma série de segmentos da indústria de transformaçáo.
\end{abstract}

Palavras-chave: Siderurgia; Consumo de Aço; Fatores sistêmicos

\section{DETERMINANTS OF STEEL CONSUMPTION: A DATA PANEL FOR COUNTRIES}

\begin{abstract}
The present study aims at analyzing how some systemic factors, such as the rates of industrialization, import, urbanization and average salary, can influence the development of the iron and steel industry, measured from countries' per capita steel consumption. To do so, 133 countries were selected based on data from World Steel Association and the World Bank for the years 1995 to 2016. The empirical strategy involves the analysis of panel data and the main results indicate the presence of unobserved heterogeneity and the need to control random effects. The coefficients of the variables were mostly positive, revealing that systemic economic factors such as average salary, urbanization, import and industrialization rates are important variables for the discussion of industrial development and countries, linked here to steel consumption, basic input of a number of segments of the processing industry.
\end{abstract}

Keywords: Iron and steel industry; Steel consumption; Systemic factors.

1 Bacharel em Ciências Econômicas pela Universidade Federal de Juiz de Fora - UFJF/Campus GV. Estagiária Superior na Usinas Siderúrgicas de Minas Gerais S.A - USIMINAS (louyze.santos@usiminas.com)

2 Doutor em Economia. Professor no Dep. de Economia. UFJF/Campus GV. Coordenador do Econúcleo Estudos Socioeconômicos. (hilton.manoel@uff.edu.br) 


\section{INTRODUÇÁO}

As indústrias do ramo siderúrgico constituem uma base forte no fornecimento de insumos às demais indústrias do setor secundário da economia, tais como: bens de consumo, de transformação, geração de energia, construção civil e automobilística (VIANA, 2017). A siderurgia no mundo teve uma evolução mais intensa entre 1950 e 1975, quando sua taxa média de crescimento anual superou $6 \%$, guiada pelo crescimento do Japão e de países da Europa e América do Norte (ANDRADE et al, 1994).

Deve-se considerar que o crescimento das empresas do ramo siderúrgico é diretamente afetado pela demanda exigida por outros ramos da indústria. Dessa forma, o consumo de aço é apontado na literatura econômica com um dos indicadores do estágio de crescimento econômico dos países (MENEZES, 2008; WARELL e OLSSON, 2009; HOLMO e NETO, 2007; OLIVEIRA e SOLLERO, 2014).

O processo se traduz, segundo Holmo e Neto (2007, p. 175), no aumento da demanda do aço na medida em que aumentam as construçóes de edifícios, as instalaçóes de meios de comunicação, a execução das obras públicas etc. Essa dinâmica, segundo Pinho (2001, p. 108), é influenciada pelas flutuaçóes macroeconômicas, como consequência de uma elevada elasticidade-renda da demanda de aço no curto prazo, influenciada pelos setores produtores de bens de capital e duráveis de consumo. O aço é fundamental porque nenhum outro material possui a mesma combinação única de resistência, formabilidade e versatilidade. Além disso, desempenha um papel crítico em diversos setores, sendo que mais da metade do aço produzido em todo o mundo vai para prédios e infraestrutura e mais de $15 \%$ são usados para atender às necessidades de transporte. O aço também tem um papel importante a desempenhar na melhoria da eficiência das fontes de energia; no crescimento, armazenamento e entrega de alimentos; na coleta, armazenamento, purificaçáo e distribuição de água (WORLD STEEL ASSOCIATION, 2019). Os dados da Figura 1 indicam essa participaçáo do consumo mundial de aço, por grandes setores. 
Figura 1 - Mercado de aço - 2017.

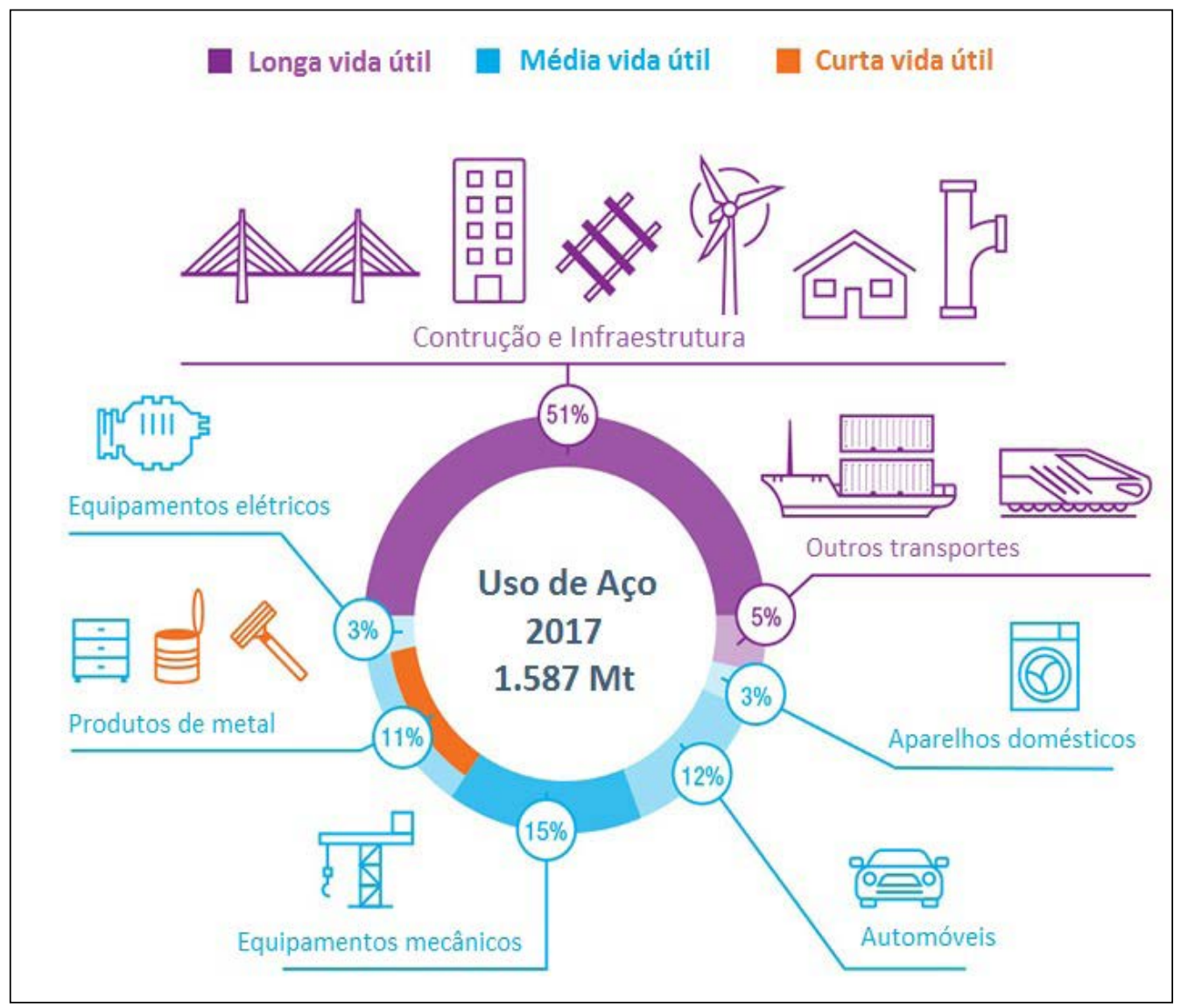

Fonte: Adaptado de World Steel Association (2019).

Há um rápido aumento do consumo de aço per capita nos países em desenvolvimento, durante a fase de industrialização destas regióes. Dentre os países em desenvolvimento, de acordo com dados da Sindicato Nacional da Indústria de Trefilação e Laminação de Metais Ferrosos - SICETEL (2016), a China se destaca como o maior produtor mundial de aço, concentrando pouco mais de $50 \%$ da produção mundial. O Brasil, por sua vez, ocupa a $8^{\text {a }}$ posição no ranking dos maiores produtores mundiais de aço. No que se refere ao consumo de aço bruto per capita (Tabela 1), os maiores valores registrados para 2016 foram para Coréia do Sul, Taiwan/China, Emirados Árabes e Djibuti. O Brasil ocupou a posição 81º, do total de 133 países $(0,36 \%)$. Já os piores indicadores estão no continente africano, com Moçambique, Sudão, Nigéria, Madagascar e Uganda. Destaca-se que a participação da Coreia do Sul no consumo per capita de aço bruto é de 4,35\% e a participação dos países africanos está abaixo de 0,04\%. 
Tabela 1 - Consumo de aço bruto per capita - 2016 (valor bruto e participação \%)

\begin{tabular}{lcc}
\hline Países & kg de aço bruto & $(\%)$ \\
\hline Coreia do Sul & 1170,5 & 4,35 \\
Taiwan, China & 931,1 & 3,46 \\
Emirados Árabes Unidos & 918,5 & 3,42 \\
Djibuti & 766,8 & 2,85 \\
\hline Brasil & $\mathbf{9 7 , 5}$ & $\mathbf{0 , 3 6}$ \\
\hline Moçambique & 9,3 & 0,03 \\
Sudáo & 9 & 0,03 \\
Nigéria & 7,4 & 0,03 \\
Madagáscar & 6 & 0,02 \\
Uganda & 3,2 & 0,01 \\
\hline
\end{tabular}

Fonte: Elaborado pelos autores a partir de dados da World Steel Association.

Assim, o estudo tem como objetivo avaliar como fatores sistêmicos podem influenciar o consumo per capita de aço dos países. Especificamente, pretende-se analisar a relaçáo entre o consumo per capita de aço e variáveis como salário médio, taxa de importação, taxa de industrialização e taxa de urbanização. Para isso, selecionou-se 133 países, com dados extraídos da World Steel Association, de 1995 a 2016. A escolha do período se deve à disponibilidade dos dados de consumo de aço bruto per capita. Critério análogo foi adotado no estudo de Oliveira e Sollero (2014). A motivação principal para a presente análise se dá pela própria importância do aço enquanto produto representativo do crescimento industrial e econômico dos países e pela relevância de ampliar os estudos empíricos sobre as relaçóes entre o consumo de aço e outras variáveis socioeconômicas.

Além desta introduçáo, o presente trabalho encontra-se estruturado da seguinte forma: a seção 2 apresenta-se um panorama geral do desenvolvimento da siderurgia no mundo; a seção3 apresenta a metodologia e os dados; na composição da seção 4 têm-se os resultados e as discussōes. Por fim, a seção 5 trata das consideraçôes finais.

\section{A INDÚSTRIA SIDERÚRGICA NO MUNDO}

As contribuiçóes teóricas aqui elencadas reforçam o papel da siderurgia como setorchave no fornecimento de insumos para as indústrias de base e de bens de consumo, estando seu desempenho altamente correlacionado ao crescimento das cidades e regióes no mundo. Além disso, destaca-se nesta seção algumas contribuiçōes empíricas sobre a relação entre consumo per capita de aço e seus determinantes econômicos.

A busca pelo maior nível de produção para atender aos elevados níveis de consumo conduziu a novas descobertas e melhoria da qualidade dos produtos. Isso é industrializar, ou seja, transformar a matéria prima em produto elaborado. A indústria predominantemente artesanal dos primeiros tempos foi aos poucos dando lugar a indústria moderna, que surgiu com a revolução industrial (BEAUD, 1987). 
Nesse contexto, a siderurgia surge como âncora para as nações que se industrializavam, uma vez que servia de base para sustentar o parque industrial nacional, sendo um importante vetor de desenvolvimento econômico e social para os países. Esse desenvolvimento da indústria siderúrgica pode ser divido em três momentos ou períodos, segundo Muylder (2001).

O primeiro momento se deu no período de 1945 a 1970. Nessa época, a Segunda Guerra Mundial havia chegado ao fim e descortinava um novo momento histórico, político e econômico para o mundo e principalmente para as potências diretamente envolvidas no conflito. O pós-guerra funcionou como incentivo para o consumo do aço, visando a reconstrução dos países envolvidos na grande guerra, fomentando a produção siderúrgica em larga escala.

O segundo momento ocorreu entre os anos de 1980 e 1988, em que houve um período de grande estagnaçáo da produção do aço. Isso se deu como consequência da crise do petróleo e do aço, a partir do surgimento de novos países industrializados em concorrência com os países do ocidente, afetando diretamente os EUA e a Alemanha Ocidental. Diante disso, houve queda do padrão exigido pelo mercado mundial.

O terceiro momento do desenvolvimento siderúrgico ocorreu após 1988. Essa época foi marcada por significavas modificações na estrutura mundial da indústria siderúrgica, devido ao processo das privatizaçóes das estatais, pelos incentivos pela abertura comercial e ainda pela dinamização do mercado. A evoluçáo do setor financeiro, acompanhado do interesse de cortes nos gastos do governo, desencadeou várias etapas de privatizaçáo pelo mundo. Devido às privatizaçóes ao cenário econômico em meados da década de 1990, países menos desenvolvidos como China, Índia e Brasil foram impactados positivamente, pois ampliaram a capacidade produtiva e a competitividade no mercado.

$\mathrm{O}$ aço permitiu criar e consolidar novos produtos e novos mercados, contribuindo para aumentar a produtividade do trabalho através do aperfeiçoamento dos maquinários. Tornou possível, ainda, a produçáo em larga escala em muitos setores industriais, com a consequente concentração industrial, além de encurtar as distâncias entre os espaços geográficos através de melhorias realizadas no transporte, sobretudo ferroviário e naval. "A indústria moderna se constituiu sobre uma estrutura de metal, particularmente o metal ferroso" (LANDES, 1969, p. 258).

A formação dos parques industriais siderúrgicos pelo mundo, desde o início do século $\mathrm{XX}$, acompanhou a expansáo da economia, destacando um maior crescimento do setor após a segunda grande guerra. Percebe-se, portanto, que a siderurgia mundial passou por momentos de crescimento (1950-1979), de queda do crescimento (1980-1999), e a partir do ano 2000 de uma nova elevação do crescimento (DE PAULA, 2002).

Segundo Resende (2011), os países considerados industrializados ou em progresso industrial são os maiores produtores de aço. Países como China, Japão, Estados Unidos, Rússia, Índia, Coreia, Alemanha, Ucrânia, Brasil e Turquia, são considerados os maiores produtores de aço, considerando o período de 1995 a 2016.

Os maiores grupos nesse setor se formaram através da intervençáo direta do Estado, cujo objetivo era formar grandes parques industriais com uma crescente produçáo, 
apresentando diferenças marcantes dos demais setores da indústria. Destaca-se nessa época uma característica que foi marcante na formação da indústria siderúrgica mundial, a aplicação de capitais nacionais, a forte presença das estatais e a ausência de multinacionais (DE PAULA, 2002).

Muylder (2001) e Ferreira (2013) fazem uma análise da ascensão da siderurgia mundial, considerando a renovação da base industrial como determinante para a expansão dos parques industriais siderúrgicos e das usinas siderúrgicas integradas, levando a uma produção em grande escala. Segundo esses autores, a fileira clássica (ou seja, baseada na usina integrada) surgiu como sinônimo de uma fase de renovação intensificada, devido às inovaçôes que apareceram no mercado ao longo do século XX, com o dinamismo do mercado do aço. Todavia, destaca-se que, devido à queda da bolsa de Nova York, em 1929, houve queda na produção do aço nos principais países. A nova ascensão da produção do aço se dá no período pós-guerra.

No que se refere ao à demanda, para Ferreira (2013) a expansão do consumo do aço per capita está relacionada com a aceleração da demanda impulsionada pelo fordismo, ou seja, pelo modelo de produção em massa de um produto, e ainda pelo consumo de bens duráveis e da construção civil, que também foram determinantes para a expansão deste consumo. Entende-se, portanto, que a siderurgia assume o papel de destaque na evoluçáo da base industrial dos países.

Na década de 1980, a indústria siderúrgica vivia um momento de total estagnação, retomando seu dinamismo com o movimento das privatizaçóes. Enquanto as empresas eram controladas pelo Estado, diversos problemas de ordem administrativa, de produção e de investimento tecnológico foram surgindo e causando uma estagnação em todo setor, que durou décadas. As privatizaçóes reestruturaram as indústrias siderúrgicas, havendo maior investimento tecnológico, reorganização administrativa, produtiva e liberdade para as empresas se reposicionarem junto ao mercado, cada vez mais competitivo e globalizado, com mudanças cada vez mais frequentes (POSO, 2015).

Essa nova fase da siderurgia mundial foi favorecida pela globalização que, através da quebra de fronteiras, facilitou o comércio internacional e a mobilidade dos fatores. A globalização proporcionou a liberdade de troca de informaçóes e uma expressiva expansão da atividade industrial. Nesse cenário, o setor siderúrgico se reestruturou por meio de fusóes, incorporaçóes e fechamentos de indústrias, desenvolvimento tecnológico, novos modelos de administração, formação de blocos regionais, internacionalização de empresas, dentre outras mudanças (BANCO NACIONAL DE DESENVOLVIMENTO ECONÔMICO E SOCIAL - BNDES, 1998).

A trajetória da indústria é influenciada por três fatores principais, segundo Coutinho e Ferraz (1993): primeiro são os "fatores internos à empresa", que são as tomadas de decisões com base na sua capacidade tecnológica; o segundo são os "fatores estruturais", que caracterizam o cenário ao redor do setor, considerando o perfil do mercado de seus consumidores, estrutura da indústria e localização geográfica; e por fim, existem os "fatores sistêmicos", que englobam as tomadas de decisões político-institucionais, macroeconômicas, sociais, infraestruturais e internacionais. 


\subsection{Condicionantes do consumo de aço}

Os estudos de Oliveira e Sollero (2014) e de Holmo e Neto (2007) são as referências básicas desta pesquisa na discussão sobre determinantes do consumo de aço. Oliveira e Sollero (2014) apresentam a Hipótese da Intensidade do Uso, que é a análise feita através do consumo por unidade monetária da economia:

\footnotetext{
"A Hipótese da Intensidade do Uso (aplicável à energia, metálicos em geral etc., aqui focada no aço), primeiramente formulada por Munlenbaum (1973), surgiu como uma alternativa aos deficientes modelos tradicionais. Esta sugere que a curva de intensidade do uso (definida como uma unidade de consumo do metálico por unidade do Produto Interno Bruto - PIB) tem a forma de um U invertido quando plotada contra o PIB per capita." (OLIVEIRA E SOLLERO, 2014, p.17).
}

O formato de $\mathrm{U}$ invertido revela que existe um período inicial de crescimento, de maturação e de declínio. Assim, pode-se fazer uma comparação com a lei dos rendimentos marginais decrescentes, ou seja, quando há aumentos contínuos da quantidade de determinado insumo de produção, de modo que seja mantido constante os demais insumos, os aumentos no volume de produção serão cada vez menores (VARIAN, 2000).

Tal inserção é expressa com importância por Oliveira e Sollero (2014, p. 18), quando o autor avalia que na fase pré-industrial a intensidade do consumo é baixa, pois as atividades econômicas concentram-se em setores como agricultura ou manufaturas intensivas em trabalho. Já nos primeiros estágios da evolução industrial, a intensidade aumenta rapidamente, uma vez que os países se urbanizam, e esse processo favorece o consumo de aço.

No processo de urbanização destaca-se o setor da construção civil, que se apresenta como uma das principais atividades consumidoras de aço. Com o desenvolvimento da economia, a intensidade do uso entra em estabilização e lento declínio, aumentando a participação do setor de serviços na composiçấo do PIB (OLIVEIRA E SOLLERO, 2014).

A urbanização é associada com a realidade socioeconômica e com o processo de crescimento da nação, ou seja, há especificidades a serem consideradas no âmbito estrutural na formação do desenvolvimento do país. Portanto, a definição da estrutura econômica é atrelada às responsabilidades do Estado em garantir um processo de expansão urbana assegurando uma estabilidade socioeconômica. Por conseguinte, entende-se a necessidade de distinçáo de países desenvolvidos e subdesenvolvidos, pois as oscilaçôes urbanas serão diferentes, logo, cada economia intensifica-se no consumo de aço de acordo com alguns fatores sistêmicos (CANO, 1989).

A curva de intensidade do uso do aço, para Oliveira e Sollero (2014), não assume o mesmo formato para todos os países. As economias subdesenvolvidas, que apresentam um processo recente de industrialização, diferem dos países desenvolvidos, dado que os primeiros exibem uma curva com pontos mais baixos de intensidade. Porém, são perceptíveis o crescimento industrial dos países subdesenvolvidos por poderem importar tecnologia dos países desenvolvidos. Para verificar tal comportamento, o autor faz uma comparaçáo das séries de consumo de aço entre os períodos de pré-industrializaçáo, industrialização, transição e pós-industrialização, para a América Latina, Europa Ocidental, América do 
Norte e Japão, nos anos de 1950 a 2005. Nota-se que o Japão alcançou níveis inferiores da intensidade do uso de aço se comparado a Europa Ocidental, e esta regiáo apresentou níveis inferiores se comparada à América do Norte.

Os estudos de Holmo e Neto (2007) indicam que à medida que a industrialização aumenta, os impactos sobre o consumo per capita de aço serão positivos e proporcionais. Consideram também que o consumo per capita de aço está relacionado à renda média da populaçấo, crescimento do país e também à distribuição de renda.

Sobre a renda média da população, como o consumo per capita de aço está inteiramente ligado à produção em diversos setores, suas oscilaçôes também dependem dessa renda. Portanto, a análise da cesta de consumo padrão de cada país é um indicador da dependência de cada região do consumo de aço. Há uma tendência progressiva que influencia as classes de baixa renda a consumirem bens de consumo duráveis na tentativa de equiparar aos indivíduos com níveis superiores de renda.

"À medida que cresce a renda dos domicílios, expande-se o conjunto dos diferentes tipos
de bens que eles consomem, ao invés de observar-se um crescimento no consumo dos bens
que já eram anteriormente consumidos. Isto tem importantes implicaçóes. [...] A compra
de um bem pelos domicílios de alta renda reduz seu preço, o que torna esse bem acessível
aos domicílios de renda mais baixa que anteriormente náo eram capazes de adquiri-lo. Esse
processo de escorregamento dos bens ajuda a indústria a decolar. A compra do bem pelos
domicílios de renda baixa, ao empurrar o preço ainda mais para baixo, ajuda a reduzir a
despesa dos domicílios de renda mais alta, permitindo que eles se movam para baixo em
direçáo ao próximo item de sua lista de compras. Através desse processo, os ganhos de
produtividade em uma indústria levam a ganhos de produtividade nas indústrias seguintes."
(MATSUYAMA, 2002, p.1039).

De acordo com Earp e Paulani. (2014), entre 1920 e 1929 houve um aumento significativo das vendas nos Estados Unidos, sendo que o consumo de aparelhos elétricos foi de 100 milhôes para 543 milhôes de dólares. Após a Segunda Guerra, esse consumo é ainda mais difundido para camadas de renda mais baixa.

Considerando a taxa de importação como um dos fatores sistêmicos, Oliveira e Sollero (2014) argumentam que esta é importante como variável explicativa de controle e encontraram uma associação pequena e positiva com a intensidade de uso do aço. $\mathrm{O}$ estudo de Haddad et al. (2004) revela que os países que possuem grande dependência das importaçóes de aço são economias com menor competitividade no mercado, e por isso recorrem a medidas que controlem a entrada de aço estrangeiro. $\mathrm{O}$ autor cita os Estados Unidos que, em 2001, assumiu a primeira colocação de maior importador de aço, seguido pela China. Mesmo que haja um aumento significativo da produção, este pode não acompanhar a própria demanda interna. Os maiores importadores de aço não deixam de ser os maiores exportadores de forma geral, evidenciando a intensificaçáo do fluxo de produtos que utilizam o aço como matéria prima.

Segundo Holmo e Neto (2007), o consumo per capita dos produtos derivados do aço aumenta em detrimento dos avanços tecnológicos dos setores que utilizam o aço como matéria-prima básica. Entende-se, portanto, que o consumo per capita de aço está intimamente ligado a dinâmicas tecnológicas e a outros fatores sistêmicos. 
Na medida em que cada país se desenvolve, o nível da intensidade do uso aumenta, ou seja, é preciso que haja um patamar mínimo de industrialização para haver a propagação do consumo inerente aos de países industrializados. Essa hipótese é baseada na curva de Kuznets (KUZNETS, 1955), que comunga do mesmo raciocínio de Rostow (1956). A curva de Kuznets admite o crescimento do consumo de materiais de base até certo ponto do PIB per capita, após este ponto haveria uma queda.

Souza (2013) considera os bens intermediários como base da produção de uma economia, como o aço. O autor destaca a importância estrutural, os retornos crescentes de escala e a alta correlação com a atividade econômica, exemplificando com a própria situação do Brasil no que se refere à intensidade do uso do aço per capita, sendo essa uma precondição para a análise da padronização de especificação dos mercados em processo de desenvolvimento.

Das contribuições empíricas, em Souza (2013) foram considerados três tipos de modelos de dados em painel. O objetivo das duas primeiras estimaçóes foi comparar os resultados de modelos com períodos de tempo diferentes, para verificar se as modificaçóes tecnológicas também modificaram o caráter da intensidade do uso dos principais setores de base. Já a terceira estimação, que aborda os países de destaques nas exportações, objetiva indicar a relação do comércio indireto dos setores demandantes de aço sobre a intensidade de uso do aço.

Os resultados do autor comprovam que as modificações estruturais a longo prazo, no setor de aço, remetem a mercados com melhor desempenho. Conclui-se que, quando o nível de desenvolvimento dos países é maior, há diminuiçóes no consumo per capita e na intensidade do uso do aço. O autor cita que após o período pós-guerra, no qual houve um alto nível de expansão do consumo, a intensidade do uso chegou a patamares limites na década de 1970.

No curso natural do desenvolvimento econômico, a partir de certo ponto a demanda por aço em construção civil, saneamento básico e transportes tendem a decrescer, já que grande parte das necessidades infraestruturais da economia costumam ser atendidas em etapas prévias do processo de desenvolvimento. Ainda assim, salvo o caso chinês e de alguns países do Oriente Médio, cuja demanda por aço extrapola a média mundial, o consumo per capita nas economias desenvolvidas continua acima da média dos países em desenvolvimento.

Resende (2011) enfatiza que o comportamento do mercado, a busca por economias de escala, às modificaçôes tecnológicas e o uso intensivo de capital são fatores que contribuem para o fortalecimento do setor siderúrgico. Além disso, entende-se que a demanda do aço aumenta de acordo com intensificaçáo dos investimentos em infraestrutura, juntamente com o nível de desenvolvimento da economia.

O maior crescimento na produção de aço foi observado na China, a partir da reforma denominada “Tse Tung” (RESENDE, 2011), quando houve uma maior abertura do setor financeiro e do comércio, além dos maiores investimentos agregados. Essa nova política chinesa almejava modernizar a sua base industrial para torná-la mais competitiva no mercado externo. Resende (2011) compara a China com a Alemanha, o Japão e a Itália, que 
ao longo do tempo perderam o potencial da capacidade instalada da siderurgia. Países como Rússia e Ucrânia foram totalmente prejudicadas nos ramos industriais devido a adoção de políticas econômicas fracassadas, além de usarem de uma tecnologia totalmente obsoleta. O autor ressalta a Índia, que se destaca pela alta disponibilidade de mão de obra, pelos altos investimentos e por fazer fronteira com a China.

Como variáveis explicativas do modelo de Resende (2011) foram consideradas a capacidade nominal de produção de aço bruto, abertura comercial para o setor siderúrgico, produçáo total de aço bruto, produçáo total de aço por processo de aciaria que utiliza conversor a oxigênio, consumo per capita de aço bruto, taxa de variaçáo do PIB real, taxa de câmbio real, preço anual do minério de ferro, preço anual do carvão mineral, e índice de preços para produtos siderúrgicos. Os resultados indicam que o desenvolvimento do setor depende de custos com as matérias primas para a fabricação de aço, das relaçóes com o mercado externo, da abertura comercial, dentre outros.

Por fim, o Instituto Aço Brasil - IABr (2012) reforça que o consumo de aço tem grande relação e impacto sobre o crescimento econômico dos países. Segundo dados de 2011 da Fundaçáo Getúlio Vargas - FGV, citados pelo Instituto, a indústria produtora de aço têm papel de destaque na alavancagem de diversas cadeias produtivas.

Pesquisas de contribuiçôes teóricas e empíricas sugerem que a dinâmica de desenvolvimento da siderurgia mundial, como de diversos outros setores, tem sido diretamente afetada por fatores econômicos e sociopolíticos, que representam importantes desafios em médio e longo prazo para o setor. Reforça-se que o foco deste trabalho está na análise de alguns fatores sistêmicos, que podem ser condicionantes do consumo de aço per capita e, consequentemente, do crescimento do setor siderúrgico.

\section{METODOLOGIA E BASE DE DADOS}

Esta seção baseia-se nas formulaçôes metodológicas de Oliveira e Sollero (2014) e Holmo e Neto (2007), sendo que o primeiro utiliza a hipótese da Intensidade do Uso para compreender a evolução do consumo de aço per capita no Brasil e o outros autores também lançam um modelo com consumo per capita de aço como variável dependente. Assim, foram selecionadas variáveis que representam fatores sistêmicos que podem influenciar o consumo per capita de aço, conforme função indica em (1):

$$
\mathrm{C}_{\mathrm{i}}=\mathrm{f}\left(\mathrm{W}_{\mathrm{i}}, \mathrm{U}_{\mathrm{i}}, \mathrm{I}_{\mathrm{i}}, \mathrm{T}_{\mathrm{i}}\right)
$$

em que $\mathrm{C}_{\mathrm{i}}$ é o consumo per capita do país $\mathrm{i}$; $\mathrm{W}$ é o salário médio; $\mathrm{U}$ é a taxa de urbanização; I é a taxa de industrialização; e T é a taxa de importação.

Com o objetivo de analisar a relaçáo entre o consumo de aço bruto per capta e fatores sistêmicos, propóe-se um modelo de dados em painel, contemplando o período de 1995 a 2016. Neste método, a mesma unidade de corte transversal é acompanhada ao longo do tempo. Justifica-se o emprego deste método pela melhor capacidade de resposta ao objetivo proposto, em relação aos modelos do tipo cross section. As vantagens do uso de dados longitudinais, segundo Hsiao (1986), é que os graus de liberdade são maiores, diminuindo assim a possibilidade de colinearidade entre as variáveis explicativas; há a oportunidade de 
controlar efeitos ligados a fatores culturais, políticas econômicas, modificaçóes conjunturais internacionais; e, por último, os dados longitudinais inibem os problemas de variáveis omitidas estarem correlacionadas com as variáveis explicativas.

Para fins de comparação dos resultados, as estimaçóes dos modelos do tipo cross section, para os anos de 1995, 2006 e 2016, são apresentadas. Assim, parte-se para o modelo do tipo Pooled Ordinary Least Square (POLS). Segundo Gujarati (2011, p. 588), a heterogeneidade entre as variáveis pode ser camuflada neste modelo, logo, poderá acarretar um problema de tendenciosidade e inconsistência dos coeficientes estimados. Com o objetivo de verificar se há presença de efeitos não-observados, aplica-se o teste de Breusch Pagan (BP). O teste, de acordo com Gujarati (2011), checa a hipótese de que não há efeitos aleatórios.

A partir da confirmação do teste BP, parte-se para a estimação com controles de Efeito Aleatório (EA) e de Efeito Fixo (EF). O EF retira todas as características que não variam ao longo do tempo; já o EA parte do pressuposto de que não é possível observar o comportamento dos indivíduos da amostra, que nesse caso são os países, pois geralmente são amostras de maior dimensão, logo, os efeitos são expressos sob a forma de uma variável aleatória. Considerando a equação (2):

$$
Y_{i, t}=\beta_{0}+X_{i, t} \beta+\varepsilon_{i, t}
$$

em que $Y_{\text {it }}$ representa o consumo per capita de aço do país i no ano t; $X_{\mathrm{it}}$ é o vetor de variáveis sistêmicas selecionadas; e $\varepsilon$ é o termo de erro aleatório.

Para escolher entre a aplicação de efeitos fixos ou aleatórios é preciso aplicar o teste de Hausman, que possui uma distribuição assintótica $X^{2}$ e assume como hipótese nula a utilização do efeito aleatório. Além dessa escolha, deve-se levar em consideração a presença de endogeneidade (WOOLDRIDGE, 2010).

Assim, considerando a inserção da variável dependente defasada, dada a influência do consumo do período passado sobre o período de análise, e os fatores sistêmicos econômicos, o modelo empírico proposto é dado por (3):

$$
Y_{t}=\beta_{1}+\beta Y_{t-1}+\beta X_{t, i}+\varepsilon_{i, t}
$$

em que $Y_{t}$ e $Y_{t-1}$ representam o consumo de aço bruto per capita e sua versão defasada no tempo, respectivamente; $\mathrm{X}_{\mathrm{t}, \mathrm{i}}$ representa o conjunto de variáveis explicativas sistêmicas, tais como salário médio, taxa de importação, taxa de industrialização e taxa de urbanização; e $\varepsilon$ é o termo de erro aleatório. Para fins de comparação, o modelo sem a inclusão da variável dependente defasada também foi analisado.

\subsection{Análise descritiva dos dados}

O critério de seleçáo dos países e do período (1995 a 2016) está baseado na disponibilidade de dados da World Steel Association e do Banco Mundial, considerando como variável dependente o consumo per capita de aço bruto e como variáveis explicativas 
o salário médio, a taxa de urbanização, a taxa de industrialização e a taxa de importação. São considerados $133^{3}$ países. A análise descritiva dos dados está na Tabela 2:

Tabela 2 - Análise descritiva dos dados

\begin{tabular}{lcccccc}
\hline \multicolumn{1}{c}{ Variável } & Descrição & Obs & Média & $\begin{array}{c}\text { Desvio } \\
\text { Padrão }\end{array}$ & Unidade & $\begin{array}{c}\text { Sinal } \\
\text { esperado }\end{array}$ \\
\hline Consumo de aço & $\begin{array}{c}\text { Consumo aparente per } \\
\text { capita de aço bruto }\end{array}$ & 2.646 & 204,38 & 233,31 & $\begin{array}{c}\text { kg de aço } \\
\text { bruto }\end{array}$ & + \\
Salário & Salário médio & 2.768 & 62,43 & 24,047 & Dólar & + \\
Importação & Taxa de Importação & 1.900 & 6,64 & 34,007 & Mil toneladas & + \\
Industrialização & Taxa de Industrialização & 2.475 & 3,88 & 7,7428 & Percentual & + \\
Urbanização & Taxa de Urbanização & 2.764 & 61,19 & 21,466 & Percentual & + \\
\hline
\end{tabular}

Fonte: Elaboração própria a partir dos dados da World Steel Association e Banco Mundial.

Sobre a variável "consumo de aço", esta tem como fonte a World Steel Association e representa o consumo $(\mathrm{kg})$ de aço bruto per capita por país. Já a variável "salário médio" é extraída do Banco Mundial e está expressa em dólares; a "taxa de urbanização" refere-se às pessoas que vivem em áreas urbanas e é calculado usando as estimativas populacionais do Banco Mundial e os índices urbanos das Perspectivas Mundiais de Urbanização das Nações Unidas. As porcentagens urbanas são o número de pessoas que residem em uma área definida como "urbana" por 100 habitantes no total. A "taxa de industrialização", extraída do Banco Mundial, inclui o valor agregado em mineração, manufatura, construção, eletricidade, água e gás. Por fim, a "taxa de importação" refere-se ao total de aço importado dividido pela produçáo total de aço com base nos dados da World Steel Association.

\section{RESULTADOS E DISCUSSÓES}

Os primeiros resultados expostos na Tabela 3 referem-se a três estimaçóes do tipo cross section. Os demais resultados (Tabela 4) se referem ao modelo POLS e aos de dados em painel com controles de Efeitos Fixo e Aleatórios. Para fins de comparação e validação, vale

3 Albânia, Argélia, Angola, Argentina, Austrália, Áustria, Azerbaijão, Bahrein, Bangladesh, Bélgica, Benim, Bolívia, Bósnia-Herzegovina, Brasil, Bulgária, Bielorrússia, Camarôes, Canadá, Chile, China, Colômbia, Congo, Costa Rica, Croácia Cuba, Chipre, República Tcheca, Dinamarca, Djibuti, República Dominicana, Equador, Egito, El Salvador, Guiné Equatorial, Estônia, Etiópia, Finlândia, França, Gabão, Geórgia, Alemanha, Gana, Grécia, Guatemala, Guiné, Honduras, Hong Kong, Hungria, Islândia, Índia, Indonésia, Irã, Iraque, Irlanda, Israel, Itália, Costa do Marfim, Japão, Jordânia, Cazaquistão, Quênia, Coréia, Kuwait, Letônia, Líbano, Líbia, Lituânia, Macedônia, Madagascar, Malásia, Malta Mauritânia, Maurícia, México, Moldávia, Mongólia, Montenegro, Marrocos, Moçambique, Mianmar, Holanda, Nova Zelândia, Nicarágua, Nigéria, Coréia do Norte, Noruega, Omã, Paquistão, Panamá, Paraguai, Peru, Filipinas, Polônia, Portugal, Catar Romênia, Rússia, Arábia Saudita, Senegal, Sérvia, Cingapura, Eslováquia, Eslovênia a, África do Sul, Coréia do Sul, Espanha, Sri Lanka, Suécia, Suíça, Síria, Taiwan, China, Tanzânia, Tailândia, Togo, Trinidad e Tobago, Tunísia, Turquia, Uganda, Ucrânia, Emirados Árabes Unidos, Reino Unido, Estados Unidos Uruguai, Uzbequistão, Venezuela, Vietnã, Mundo, Iêmen, Zaire, Zâmbia, Zimbábue. 
destacar que estas análises da Tabela 4 são feitas de duas formas, a primeira não considera a variável dependente defasada e a segunda já contempla.

Especialmente sobre as análises cross-section, para os anos de 1995, 2006 e 2016, verifica-se que o coeficiente da variável "salário médio" possui sinal esperado positivo e é estatisticamente significativo para os três períodos. A variável taxa de importação é estatisticamente significativa apenas para o ano de 2016, e com coeficiente negativo, ou seja, fora do esperado. Já a taxa de industrialização é positiva, mas não é estatisticamente significativa em todos os três períodos. Por fim, a taxa de urbanização é positiva e significativa para os anos de 1995 e 2016.

Tabela 3 - Condicionantes consumo de aço - modelos cross section

\begin{tabular}{l|c|c|c}
\hline Consumo per capita de aço & 1995 & 2006 & 2016 \\
\hline Salário & $0,9266^{* *}$ & $1,7448^{* * *}$ & $1,3202^{* * *}$ \\
& $(0,4085)$ & $(0,2885)$ & $(0,3512)$ \\
Importaçáo & $-0,0834$ & $-0,0736$ & $-0,1313^{* *}$ \\
& $(0,0842)$ & $(0,0699)$ & $(0,0584)$ \\
Industrialização & 0,0534 & 0,1896 & 0,0984 \\
& $(0,0947)$ & $(0,1262)$ & $(0,0715)$ \\
Urbanização & $1,4801^{* * *}$ & 0,2702 & $0,6630^{* *}$ \\
& $(0,5137)$ & $(0,3119)$ & $(0,3113)$ \\
Constante & $-5,2268^{* * *}$ & $-3,5465^{* * *}$ & $-3,1084^{* * *}$ \\
& $(1,3800)$ & $(1,4911)$ & $(1,4752)$ \\
\hline Observaçóes & 47 & 69 & 55 \\
Países & 133 & 133 & 133 \\
$\mathrm{R}^{2}$ & 0,5815 & 0,5009 & 0,4994 \\
\hline
\end{tabular}

Notas: 1) entre parênteses encontra-se o desvio-padrão. 2) ${ }^{* * *}$, **, *: significativo a $1 \%, 5 \%$ e $10 \%$. Variáveis na forma logarítmica.

Fonte: Elaboração própria.

Assim, confirma-se a associação direta entre salário, urbanização e o consumo per capita de aço, como destacado Oliveira e Sollero (2014) e de Holmo e Neto (2007). Contudo, estes modelos do tipo cross-section são relativamente limitados para apuração dessas relaçôes, sendo importante a próxima análise com dados longitudinais.

A próxima análise se refere ao modelo POLS (Tabela 4, colunas 1 e 4). Os resultados indicam que as variáveis salário médio e taxa de industrialização possuem coeficientes positivos e estatisticamente significativos a níveis de $1 \%$ e $5 \%$, respectivamente. Já para as variáveis importação e urbanizaçáo, ambas são significativas no modelo (1), a primeira apresenta sinal negativo e a segunda é positiva, conforme relaçóes indicadas nas estimaçóes por cross-section. Sobre a variável dependente defasada (modelo 4), apresenta coeficiente 
significativo e positivo, ou seja, o consumo de aço do período passado se associa diretamente ao consumo do período atual de análise.

Dada a hipótese de presença de heterogeneidade não observada, parte-se para a análise do teste de Breusch Pagan. O resultado indica que há efeitos não observados, levando-se à necessidade de controles de efeito fixo ou aleatório. Para identificar qual efeito se ajusta melhor aos dados, aplica-se o teste de Hausman, o qual confirma a necessidade de controle dos efeitos aleatórios. Assim, as análises devem se concentrar nos modelos (2) e (5).

Tabela 4 - Condicionantes de consumo - dados em painel - 1995 a 2016.

\begin{tabular}{lcccccc}
\hline \multirow{2}{*}{$\begin{array}{l}\text { Consumo per } \\
\text { capita de aço }\end{array}$} & $(1)$ & $(2)$ & $(3)$ & $(4)$ & $(5)$ & $(6)$ \\
\cline { 2 - 7 } Salário & POLS & EA & EF & POLS & EA & EF \\
& $1,4026^{* * *}$ & $1,1584^{* * *}$ & $1,0423^{* * *}$ & $0,0518^{* *}$ & $0,0518^{* *}$ & $0,3306^{* * *}$ \\
Importaçáo & $(0,0725)$ & $(0,0896)$ & $(0,0966)$ & $(0,0259)$ & $(0,0234)$ & $(0,07163)$ \\
& $-0,0989^{* * *}$ & $0,0264^{*}$ & $0,0427^{* * *}$ & 0,00074 & 0,0007 & $0,0185^{*}$ \\
Industrializaçáo & $(0,0141)$ & $(0,0142)$ & $(0,0148)$ & $(0,0043)$ & $(0,0040)$ & $(0,0105)$ \\
& $0,0526^{* *}$ & $0,0284^{* * *}$ & $0,0282^{* * *}$ & $0,0384^{* * *}$ & $0,0384^{* * *}$ & $0,0342^{* * *}$ \\
Urbanização & $(0,0252)$ & $(0,0107)$ & $(0,0106)$ & $(0,0065)$ & $(0,0070)$ & $(0,0076)$ \\
& $0,5736^{* * *}$ & $1,0547^{* * *}$ & $1,4062^{* * *}$ & 0,0128 & 0,0128 & $0,3688^{* * *}$ \\
Consumo açot-1 & $(0,0817)$ & $(0,1550)$ & $(0,2135)$ & $(0,0286)$ & $(0,0203)$ & $(0,1591)$ \\
& - & - & - & $0,9589^{* * *}$ & $0,9589^{* * *}$ & $0,6861^{* * *}$ \\
\hline Obs & - & - & - & $(0,0129)$ & $(0,0081)$ & $(0,0199)$ \\
\hline Dummies de ano & 1291 & 1291 & 1291 & 1242 & 1242 & 1242 \\
Países & sim & sim & sim & sim & Sim & sim \\
$\mathrm{R}^{2}$ & 133 & 133 & 133 & 133 & 133 & 133 \\
\hline
\end{tabular}

Notas: 1) entre parênteses encontra-se o desvio-padrão. 2) ${ }^{* * *}{ }^{* *},{ }^{*}$ : significativo a $1 \%, 5 \%$ e $10 \%$. Uso do software Stata 12. Variáveis na forma logarítmica.

Fonte: Elaboração própria.

A partir dos modelos com controles de EA (2) e (5), os resultados indicam que a taxa de industrialização é positivamente relacionada com o consumo per capita de aço para ambos modelos os modelos. Esses resultados podem ser analisados à luz das açóes políticoeconômicas (fatores sistêmicos). As transformaçóes no setor siderúrgico se devem, dentre outras causas, ao aumento dos incentivos para instalação de parques industriais. Apesar da crise de 2008, países como o Brasil se destacaram nessa oferta de incentivos setoriais. Neste, as obras de infraestrutura no setor de construçáo civil foram destaques (programa “minha casa, minha vida”, obras para os jogos da Copa de 2014). Conforme Instituto Aço Brasil - IABr (2012), o aumento do nível de industrialização está relacionado ao aumento do nível de consumo de aço per capita, ou seja, a relação entre o consumo per capita de aço e a taxa de industrialização está atrelada aos ciclos industriais. Conforme Holmo e Neto 
(2007), mesmo que haja uma defasagem com relação a evolução industrial de cada nação, de maneira geral todos já possuem um consumo mínimo considerável de aço.

Sobre a taxa de importação e a taxa de urbanização, os resultados indicam uma relação positiva em ambos os modelos ( 2 e 5), mas estatisticamente significativa apenas no modelo 2. Sua relação direta com o consumo per capita de aço é justificada pelo fato dos países com baixa competitividade no mercado externo demandarem relativamente mais aço por conta de carências tecnológicas no setor siderúrgico. Além disso, mesmo que os países sejam eficientes em seus desempenhos tecnológicos, podem não conseguir suprir a própria demanda interna por aço, logo, recorrem às importaçóes.

Já os resultados da taxa de urbanização podem ser justificados por conta das mudanças no padrão de consumo e dos novos arranjos estruturais que se iniciam por conta do processo de redistribuição populacional, os quais são fundamentados em fatores sistêmicos (políticos, econômicos e institucionais).

Sobre o coeficiente da variável "salário médio", este se mostrou positivo e estatisticamente significativo para ambos modelos (2 e 5). Isso corrobora as análises de Neves e Camisasca (2013), que indicam o Brasil, os países europeus e asiáticos como exemplos de regióes que apresentaram um maior consumo de produtos feitos de aço em períodos de ascendência dos salários. As políticas de incentivo ao crédito ou de aumentos diretos elevam o consumo de bens duráveis, que por sua vez, aumentam a demanda do insumo aço.

Os modelos com controle de efeitos fixos (3 e 6) foram mantidos para fins de comparação. Todos os coeficientes das variáveis são estatisticamente significativos e apresentaram o mesmo sentido de associação em relação ao consumo de aço per capita.

\section{CONSIDERAÇÓES FINAIS}

O conjunto de fatores sistêmicos é diferente para cada país, sendo este um dos responsáveis pelo crescimento econômico em cada região. O presente trabalho teve por objetivo analisar a relação entre condicionantes econômicas selecionadas e o consumo de aço per capita, sendo esta variável um indicador representativo para o desenvolvimento urbano, industrial e econômico dos países.

O período de análise contempla os anos de 1995 a 2016, baseado na disponibilidade dos dados. Para a compreensão dos resultados estatísticos, uma revisão bibliográfica envolvendo o setor siderúrgico e seus condicionantes foi empregada. Não se pode desconsiderar a importância da ação do Estado para a industrialização e ascensão da siderurgia nos países. $\mathrm{O}$ aço assumiu progressivamente um papel de destaque no mercado por conta de seu consumo crescente como matéria-prima básica de diversos outros setores produtivos.

Os fatores condicionantes do progresso do setor siderúrgico podem ser divididos entre internos à empresa, sistêmicos e os fatores estruturais. No presente estudo concentrouse na análise de alguns fatores econômicos sistêmicos, fundamentando-se especialmente nas contribuiçóes empíricas de Oliveira e Sollero (2014) e de Holmo e Neto (2007).

Os principais resultados sugerem que há uma associação significativa e positiva de alguns dos fatores sistêmicos, tais como o salário médio, a taxa de importação de aço, a taxa 
de industrialização e a taxa de urbanização, as quais podem determinar o nível do consumo de aço bruto per capita dos países. As variáveis salário médio, taxa de industrialização e consumo de aço do período anterior apresentaram coeficientes significativos e positivos, ou seja, o crescimento econômico do país está diretamente relacionado ao consumo de aço, que por sua vez se configura também como proxy para industrialização e crescimento econômico. Já as variáveis que indicam as taxas de urbanização e importação foram positivas, porém não significativas. A relação direta também era a esperada, conforme os trabalhos de Oliveira e Sollero (2014) e de Holmo e Neto (2007).

A partir deste trabalho confirma-se a importância de analisar de forma sistemática os efeitos de fatores sistêmicos, políticos, econômicos ou institucionais sobre o consumo de aço e, consequentemente, sobre o desenvolvimento produtivo, industrial e urbano das regiôes. Além disso, cabe destacar as limitaçóes desse estudo no que se refere ao conjunto de variáveis selecionadas como condicionantes do consumo de aço per capita, deixando espaço para futuras pesquisas que poderão incorporar novas dimensóes e controles para avaliação da evolução do setor siderúrgico.

\section{REFERÊNCIAS}

ANDRADE, M. L. A.; CUNHA. L. M. S.; VIEIRA, J. R. M. A siderurgia brasileira no contexto mundial. Revista BNDES, Rio de Janeiro, v.1, n.1, p.71-96, jun, 1994.

BANCO NACIONAL DE DESENVOLVIMENTO ECONÔMICO E SOCIAL - BNDES. Siderurgia - Desempenho e Perspectiva. Rio de Janeiro, Relatório do BNDES, 1998

BANCO MUNDIAL. Dados. Disponível em https://data.worldbank.org/

BEAUD, M. História do capitalismo de 1500 até nossos dias. SP, Editora Brasiliense, 1987.

CANO, W. Urbanização: sua crise e revisão de seu planejamento. Revista de Economia Política, v. 9, n. 1, p. 62-82, 1989.

COUTINHO, L. G.; FERRAZ, J. C. Estudo da competitividade da indústria brasileira. Brasília: IE/UNICAMP-IEI/ UFRJ-FDC-FUNCEX, 1993.

DE PAUlA, G. M. Cadeia Produtiva de Siderurgia. Estudo de Competitividade por Cadeias Integradas: um esforço coordenado de criaçáo de estratégias compartilhadas. Brasília: Ministério de Desenvolvimento, Indústria e Comércio Exterior e Instituto de Economia da Unicamp, 2002.

EARP, F. DE SÁ; PAULANI, L. M. Mudanças no consumo de bens culturais no Brasil após a estabilizaçáo da moeda. Nova Economia, v. 24, n. 3, p. 469-490, 2014. 
FERREIRA, C. G. A evolução das normas técnicas de produção na siderurgia: principais tendências históricas. Nova Economia, v. 3, n. 1, 2013.

GUJARATI, D. N. Econometria Básica. Editora: MC Graw Hill Bookman, 924 p., 2011.

HADDAD, E. A.; MORAIS, A. G.; OLIVEIRA, S. J. M.; TEIXEIRA, W. M. Medidas protecionistas na siderurgia norte-americana: impactos setoriais e regionais. XXXII Encontro Da Associação Nacional dos Centros De Pós-Graduação em Economia, 2004.

HOLMO, R. Z.; NETO, C. M. Cenários futuros para a indústria siderúrgica da China: oportunidades e ameaças. Parcerias Estratégicas, v. 12, n. 25, p. 175-212, 2007.

HSIAO, C. Analysis of panel data. Cambridge: Cambridge University Press, 1986.

INSTITUTO AÇO BRASIL - IABr Relatório de Sustentabilidade. 2012.

Disponível em http://www.acobrasil.org.br/site/portugues/biblioteca/relatorio_ sustentabilidade_2012.pdf

KUZNETS, S. Economic growth and income inequality. The American economic review, p. 1-28, 1955.

LANDES, D. The Unbound Prometheus: Technological Change and Industrial Development in Western Europe from 1750 to the Present. Cambridge University Press, 1969.

MENEZES, J. O. R. Produçáo Regional de Aço. Tese de Doutorado. Universidade Federal do Rio de Janeiro, UFRJ, 2008.

MATSUYAMA, K. The rise of mass consumption societies. Journal of Political Economy, vol. 110, no 5, 2002.

MUYLDER, C. Indústria Siderúrgica: reestruturação e competitividade. UFV, 2001.

NEVES, O. R.; CAMISASCA, M. M. Aço Brasil: uma viagem pela indústria do aço. Belo Horizonte: Escritório de Histórias, 192 p., 2013.

OLIVEIRA, F. N; SOLLERO, L. P. V. Consumo de Aço no Brasil: um modelo baseado na técnica da intensidade do uso. Trabalhos para Discussáo, 358. Banco Central do Brasil, 2014. Disponível em https://www.bcb.gov.br/pec/wps/port/TD358.pdf

PINHO, M. S. Reestruturação produtiva e inserção internacional da siderurgia brasileira. Tese de Doutorado. Instituto de Economia - Unicamp, Campinas, 2001. 
POSO, A. T. A Siderurgia Brasileira e Mundial: o desenvolvimento desigual recente. Tese (Pós-Graduação em Geografia Humana) - Faculdade de Filosofia, Letras e Ciências Humanas, Universidade de São Paulo, São Paulo, 311 p., 2015.

RESENDE, M. C. Estudo do comportamento da produçáo de aço bruto entre os anos de 2000 a 2008: uma análise com dados em painel para os dez maiores países produtores. Dissertação (mestrado) - Universidade Federal de Santa Catarina, Centro Sócio Econômico, Santa Catarina, 2011.

ROSTOW, W. W. The take-off into self-sustained growth. Economic Journal, v. 66, n. 261, p. 25- 48, 1956.

SINDICATO NACIONAL DA INDÚSTRIA DE TREFILAÇÃO E LAMINAÇÃO DE METAIS FERROSOS- SICETEL. Análise do Mercado do Aço, São Paulo, 2016.

SOUZA, D. T. Demanda e intensidade do uso de materiais básicos em economias recentemente industrializadas. Tese. (Programa de Pós-Graduação em Engenharia de Produção). Universidade Federal De São Carlos. 2013.

VARIAN, H.R. Microeconomia: Princípios Básicos. Rio de Janeiro: Campus, 2000.

VIANA, F. L. E. Indústria Siderúrgica. Caderno Setorial ETENE, v.2, n.13, p.1-13, agosto, 2017.

WARELL, L.; OLSSON, A. Trends and developments in the intensity of steel use: an econometric analysis. In: Securing the Future \& ICARD. Curran Associates, Inc., 2009.

WOOLDRIDGE, J. M. Introdução à Econometria: uma abordagem moderna. Editora: Cengage Learning, 2010. 701 p.

WORLD STEEL ASSOCIATION. Steel Statistical Yearbook. Disponível em https:// www.worldsteel.org/steel-by-topic/statistics/steel-statistical-yearbook-.html

. Steel Markets. 2019. Disponível em https://www.worldsteel.org/steel-by-topic/ steel-markets.html 